\title{
The resolved mystery of tardigrades
}

\begin{abstract}
Tardigrades, also known as 'Water bears' or 'Space Bears' are famous for their ability to survive in extreme environmental conditions. With incredible ability to survive at a range of temperature between $-272^{\circ} \mathrm{C}$ to $150^{\circ} \mathrm{C}$, these small eight legged animals are considered as one of the toughest organisms of the world. There are several records of survival of these animals under high pressure, UV exposure and even in space under cosmic radiation. For decades it remained a mystery how tardigrades can tolerate the extreme environmental conditions. Afteryears of research, it was found that tardigrades dry out and turn their entire body into a glass like structure at very low temperature, termed as "Bio-glass" to shut down all their metabolic processes. Later by rehydrating, the creatures bring back life in them. Finally researchers have identified the key protein in tardigrades which helps them to survive at extreme low temperature. The genome of several tardigrades species has been sequenced like 'Ramazzottius varieornatus', 'Hypsibius dujardini'. The sequenced genome provides evidences of expression of tolerance related genes and horizontal gene transfer in the animals helping them to survive in extreme environmental conditions with these key genes. The research also focuses on how a unique protein from tardigrades can be used in fields of agriculture, pharmaceuticals and biotechnology in future.
\end{abstract}

Keywords: tardigrades, expression sequence tag, extremophile organisms, baltic sea, Antarctica
Volume 4 Issue 2 - 2017

\author{
Oisorjo Chakraborty, Pranab Roy \\ Department of Biotechnology, Haldia Institute of Technology, \\ India
}

Correspondence: Pranab Roy, Department of Biotechnology, Haldia Institute of Technology, India, Tel 9933037099, Email prpranabroy94@gmail.com

Oisorjo Chakraborty, Department of Biotechnology, Haldia Institute of Technology, India, Email chako.oisorjo@gmail.com

Received: April 21, 2017 | Published: May 19, 2017
Abbreviations: EST, expression sequence tag; TDPs, tardigrade specific intrinsically disordered protein; IDP, intrinsic disordered protein; CAHS, cytoplasmic abundant heat soluble; SAHS, secondary abundant heat soluble; ESA, european space agency; HGT, horizontal gene transfer

\section{Introduction}

The phylogenetic position of tardigrade is a controversial and uncertain field among scientists. The tiny animals are considered to belong to an independent phylum called "Tardigrada". Recent phylogenomics studies based on expression sequence tag (EST) and micro RNAs (miRNAs) have confirmed the phylogenetic position of tardigrades as a sister group of the arthropods. ${ }^{1}$ Tardigrades are segmented micro animals which can be up-to $1 \mathrm{~mm}$ in body length when they are adult. These small animals have a hemocoel type of fluid-filled body cavity, a complete digestive tract, and a lobed dorsal brain. The tiny animals mostly prefer eating moss, algae, and lichens from water. ${ }^{2}$ Approximately 900 species have been reported of these animals found throughout the world such as marine environments (cold sea of Antarctica), fresh water and terrestrial environment (desserts, polar desserts, lake basins). ${ }^{2-4}$

\section{Amazing characteristics shown by tardigrades}

Tardigrades gathered attentions from scientists due to their ability to survive extreme temperature variation, dehydration, radiation and ability to survive in space too. But the biggest question raised is how a single group of animals can have potentials to become nearly indestructible. Before answering the question it is important to mention that tardigrades are entirely different animals from the extremophile organisms. Extremophile micro-organisms are adapted to the extreme conditions, eg. Thermophiles from hot springs can live there naturally with all biological functions smoothly running. ${ }^{5}$ But for tardigrades, they are not adapted to extreme environment; they just change their morphological state to avoid death. In extreme conditions such as heat, cold, UV ray, high pressure or vacuum, tardigrades dry themselves through a process called 'Anhydrobiosis' and enter a state of extreme dryness termed as 'Desiccation'. Later in presence of water the body can again rehydrate to gain back its normal functions.

\section{Tardigrades in low temperature}

Species of tardigrades are found from mountains of Himalaya, Baltic Sea, and Antarctica and even in the ice caps of Polar Regions. As moss is mainly consumed by these small animals, sometimes the tardigrades are found in dry mosses from ice. In icy glaciers often small water fiilled holes are formed due to heat absorption from the accumulation of wind blowing on glacier surface. These water filled cylindrical holes are called 'Cryoconite'. Cryoconites have the exact suitable environment for the living of moss, algae and tardigrades. ${ }^{6}$ Several species of tardigrades have survived the low temperature of $-18^{\circ} \mathrm{C}$ to $-20^{\circ} \mathrm{C}^{7}$ ovserved that tardigrades dry out in cold temperature and form a typical tun or round ball like structure. The formation of tun is very important to maintain the dry state by reducing water loss and to protect the internal organs. ${ }^{7}$ The process by which tardigrades enters a dry state is also called 'cryptobiosis' and the extreme dry conditions are explained as a stage of 'desiccation'. In 2013 it was observed that during the process of desiccation, tardigrades or water bears go through a process of muscle reorganization to change their structure. The changes in shape were observed with confocal laser scanning elctron microscopy shown in Figure 1 and 3D constructs. ${ }^{8}$ This experiment supports the claims of tun formation and entire body contraction by Jonathan C Wright. During extreme dehydration (desiccation), tardigrades coat themselves with a glass like material, which is often termed as 'Biological glass'. ' This glass like structure helps the tardigrades to survive foryears in the state of desiccation by protecting all internal organs and key proteins of the body. In 2016, a team of scientists from Japan had been able to bring back life in tardigrades which were in a frozen state for 30years in very 
low temperature in Antarctica. The species Acutuncus antarcticus of water bear was in frozen state in a dried moss sample for 30.5years since 1983 at a low temperature of $-20^{\circ} \mathrm{C}$. There were two tardigrades in the sample and these were named SB-1 and SB-2 (SB stands for sleeping beauty). The tardigrades were re-hydrated from frozen state by keeping them in $15^{\circ} \mathrm{C}$ in dark. Later the SB-2 died as it did not eat much but the tardigrade SB-1 showed amazing progress. On the first day of rehydration after being in inactive frozen state for 30 years, the legs of the creature started moving. Eventually the body movement was observed, the tardigrade, SB-1 started eating moss and on the 21 st day it was also able to produce eggs. Later the eggs also produced healthy newborns. This experiment holds the record of longest survival of an animal. Scientists were confused about what property of the animals helped them to resurrect from a frozen state even after 30years. It was proved before that they undergo several morphological changes like tun formation or glass like dried structure formation due to desiccation. ${ }^{10}$ But what was the factor that helped them to rehydrate and bring back to life still remained a mystery.

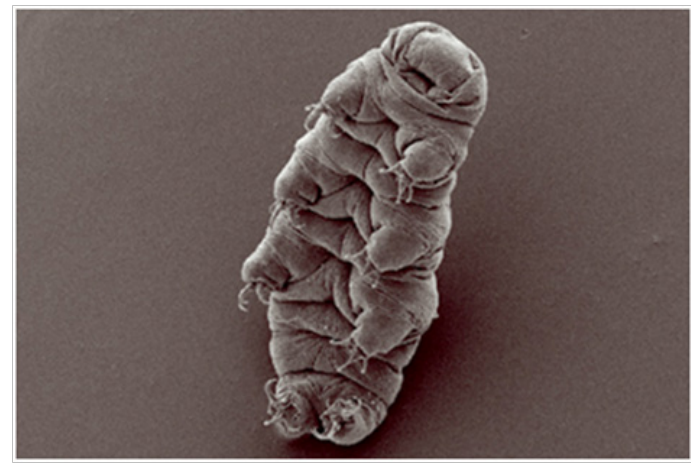

Figure I Image of a tardigrade under scanning electron microscope.

\section{The resolved mystery}

It is amazing that these animals have power to hold its life in frozen ice crystal for 30years where the biggest risk can be formation of sharp ice crystal edges causing damage to the cells. Even due to cryopreservation to save the cell from this kind of damages the cooling rate is kept very low and cryopreservants are used. ${ }^{10}$ So, it is significant to call the tardigrades 'natural alive cryopreservant animals'. Previously it was thought that to endure desiccation like many other animals tardigrades accumulate non-reducing disaccharide 'Trehalose' Figure 2. But after being in frozen state (anhydrobiosis) a few species of tardigrades showed significant amount of trehalose but few did not show the presence of trehalose in them at all. So, trehalose can not be the answer for every tardigrade in general. ${ }^{11,12}$ Recently a group of scientists have identified the key protein in the tardigrades which helps them to enter in the frozen state and again to rehydrate back in life form. It has been proved from the experiments that a protein called "Tardigrade-specific Intrinsically Disordered Protein" (TDPs) is essential for desiccation tolerance. This protein is also called "Intrinsic disordered protein" or (IDP). TDP is responsible for the formation of glass like structure in the tiny animals. The protein helps the tardigrades in gradual drying and again to bring back their alive form by rehydrating. In the experiment when the TDP protein genes were over expressed in tardigrades, they showed a better desiccation tolerance compared to the tardigrades with normal level of TDP. ${ }^{13}$ One important advantage is that when this exact protein is separated and expressed in other heterologous systems they still show the same properties of the protein. As an example when the tardigrades protein genes were expressed in human HeLa cell line, then the human DNA showed extreme properties of tolerance against radiaton. ${ }^{14}$ In future there may be experiments done by inserting tardigrades genes into human, to help human species to tolerate extreme environmental conditions. The TDP genes can be used to create crops which will be resistant to drought (Figure $3 \&$ Figure 4). Many vaccines and medicines are costly because of the storing cost in cold, if the protein can be used in right way, in future there may be no need of cold storing. Scientists have already expressed the IDP genes in yeast and bacterial cells and the transgenic micro-organisms are found to be able to tolerate extreme low temperature and dry conditions by producing glass proteins. ${ }^{13,15,16}$

\section{Tardigrades under high temperature and radiation}

Tardigrades are found to survive under high temperature range of $80^{\circ} \mathrm{C}$ to $100^{\circ} \mathrm{C}$. The toleration of high temperature is also carried out through the same process anhydrobiosis, where the animals enter into desiccated state. The studies provide information about how a glass transition helps the creatures to avoid death at high temperatures. ${ }^{17} \mathrm{~A}$ recent study of anhydrobiotic tardigrades shows that they contain two conserved heat protein families. The proteins are called Cytoplasmic Abundant Heat Soluble (CAHS) and Secondary Abundant Heat Soluble (SAHS) proteins. Both of the proteins are heat soluble, where CAHS is intrinsically unstructured and the SAHS is rich with beta sheets. In higher temperature both of these proteins reconstruct themselves with alpha helical protein structures, which suggest the new structure helps them to adapt the extreme conditions such as high heat and dry environment with less water. ${ }^{18}$ There are also evidences that these animals can survive under radiation and UV exposure from the experiments carried out by European Space Agency. ${ }^{19,20}$

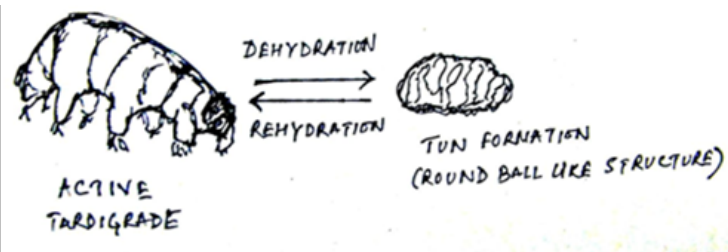

Figure 2 Structural change of tardrigrades during desiccation.

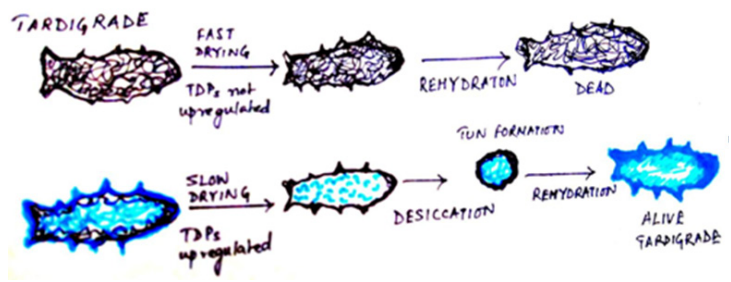

Figure 3 TDP regulation in tardigrades to keep themselves alive.

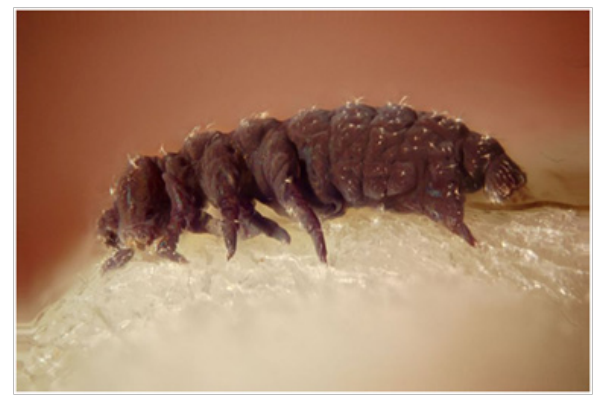

Figure $4 \mathrm{~A}$ tardigrade from the hot spring of California. 


\section{Tardigrades in space}

BIOKon in Space (BIOKIS) was a project conducted in 2011 that involved seven experiments sponsored by the Italian Space Agency (ASI-Agenzia Spaziale Italiana) in the areas of cellular biology, radiation and radioprotection, aging, germination and plant growth. The entire experiment was sponsored by NASA and one of the alive specimen used by the agency in space for testing were tardigrades. Obviously tardigrades were chosen for finding out if it can survive at very low temperature, high radiation and several extreme environmental conditions of space. The tests were carried out using tardigrades in special container in space station. Two species of tardigrades showed their ability to survive at extreme stressful conditions of space. ${ }^{21}$ 'Paramacrobiotus richtersi' and 'Ramazzottius oberhaeuseri' these two species showed ability to survive by desiccation in stressful conditions of space by changing their enzyme activity and fatty acid compositions. ${ }^{22}$ In another experiment conducted by European Space Agency (ESA) at low earth orbit, two species of tardigrades, 'Richtersius coronifer' and 'Milnesium tardigradum' were exposed to two different UV spectral ranges of UV 280-400nm and UV 116.5-400nm. These two species showed ability to survive at vacuum and at high UV radiation by drying up and rehydrating back later. ${ }^{19}$ The properties through which the animals can survive at extreme conditions of space like low temperature, lack of oxygen by creating a protection shield around, has made tardigrades an ideal organism for space research. ${ }^{23}$

\section{Genome of tardigrades}

It is obvious that features shown by any animal are controlled by their key genes. Several species of water bears have been sequenced and size of their genome varies between them. ${ }^{24}$ Some specific species of tardigrades (Hypsibius dujardini) showed that their genomes contained almost $17.4 \%$ of foreign DNA from several other species. There were partial sequence matches from foreign species like bacteria, plants, fungi, archaea. In contrast, most of the animals show less than $1 \%$ of foreign DNA in their genomes. This $1 \%$ of foreign DNA too is mainly transferred through 'vertical gene transfer' process from their ancestors through the process of evolution in most of the animals. It was exceptional how tardigrades, the tiny animals can have $17.4 \%$ of foreign genes in them where most of the other animals are found to have less than $1 \%$ of foreign genes. Later it had been found that tardigrades mainly obtained that much amount of foreign DNA through the process of horizontal gene transfer (HGT). It had been also reported that 6000 of the foreign genes of tardigrades were transferred through HGT process from other species giving them unique characters. ${ }^{25}$ Though there are controversies about this as another group of researchers have demanded that most of the foreign DNA from the previous results came from contaminants. Still those researchers have come to the conclusion that there is $1-2 \%$ of foreign DNA in that specific tardigrades species transferred through HGT process. ${ }^{26}$ Another species of tardigrades has been sequenced named Ramazzottius varieornatus. It has been found that the genome of this tardigrade contains almost $1.2 \%$ of foreign DNA transferred through horizontal gene transfer. The foreign DNA also promotes stress and damage tolerance in the animals. During the research few unique tardigrades proteins have been discovered. The unique DNA sequence of the proteins was expressed in human cell line and the transgenic cells were able to suppress the DNA damage caused by $\mathrm{X}$-ray and radiation when they were tested. ${ }^{27}$

\section{Conclusion}

Researchers have been studying tardigrades since a long time and one by one their mysterious properties have been resolved with the progress of science. As this animal shows extremely superior characters which makes it entirely different from others of animal kingdom, with more researches, new facts can be known about water bears. On one end after discovering the key protein genes which makes the animal nearly indestructible, there could be more research done to use these genes in creating transgenic crops and animals having the same extreme tolerance property. The refrigeration of vaccine and drugs may have a potential alternative if the properties of the protein from tardigrades can be used in a proper way. At the other end with amazing survival records tardigrades also provide scopes to test the living organisms in space research and to test the lives on other planets too. There are still confusions about the exact amount of foreign DNA in Tardigrades and role of those genes in them. So, for a clear idea more research needs to be done with various species of tardigrades to get an overall knowledge of their genome.

\section{Acknowledgements}

None.

\section{Conflict of interest}

Author declares that there is no conflict of interest.

\section{References}

1. Campbell LI, Rota-Stabelli O, Edgecombe GD, et al. MicroRNAs and phylogenomics resolve the relationships of Tardigrada and suggest that velvet worms are the sister group of Arthropoda. Proc Natl Acad Sci USA. 2011;108(38):15920-15924.

2. Nelson DR. Current Status of the Tardigrada: Evolution and Ecology. Integr Comp Biol. 2002;42(3): 652-659.

3. Guidetti R, Rebecchi L, Cesari M, et al. Mopsechiniscus franciscae, a new species of a rare genusof Tardigrada from continental Antarctica. Polar Biology. 2004;37(9):1221-1233.

4. B Singh, Gautam SK. Textbook of Animal Biotechnology. The Energy \& Resources Institute, India; 2013.

5. Takai T, Nakamura K, Toki T, et al. Cell production by a proliferation at $122^{\circ} \mathrm{C}$ and isotopically heavy $\mathrm{CH} 4$ hyperthermophilic methanogen under high-pressure cultivation. Proc Natl Acad Sci USA. 2008;105(31):10949-10951.

6. Sømme L. Anhydrobiosis and cold tolerance in tardigrades. Norway: Dept of Biology, University of Oslo; 1996;93:349-357.

7. Wright JC. Desiccation tolerance and water-retentive mechanisms in tardigrades. J Experimental Biology. 1988;142:267-292.

8. Halberg KA, Jørgensen A, Møbjerg N. Desiccation Tolerance in the Tardigrade Richtersius coronifer Relies on Muscle Mediated Structural Reorganization. PLoS One. 2013;8(12):e85091.

9. Matt Atherton. Micro-animal water bears encase themselves in 'biological glass' to go decades without hydration. 2015.

10. Tsujimoto M, Imura S, Kanda H. Recovery and reproduction of an Antarctic tardigrade retrieved from a moss sample frozen for over 30years. Cryobiology. 2016;72(1):78-81.

11. Freshney RI. Culture of Animal Cells: A Manual of Basic Technique and Specialized Applications. 6th ed. Cell \& Molecular Biology. 2011.

12. Hengherr S1, Heyer AG, Köhler HR, et al. Trehalose and anhydrobiosis in tardigrades-evidence for divergence in responses to dehydration. FEBS J. 2008;275(2):281-288.

13. Boothby TC, Tapia H, Brozena AH, et al. Tardigrades Use Intrinsically Disordered Proteins to Survive Desiccation. Mol Cell. 2017;65(6):975-984. 
14. Jason Bittel. Tardigrade protein helps human DNA withstand radiation. Nature. 2016.

15. Inter Aksyon. Microscopic invertebrates show drought-resistant benefits. 2016.

16. We Can Now Harness the Tardigrade's Strangest Superpower-and Give It to Other Organisms Turn them into living glass. $B B C C R E W .2017$.

17. Hengherr S, Worland MR, Reuner A, et al. High-temperature tolerance in anhydrobiotic tardigrades is limited by glass transition. Physiol Biochem Zool. 2009;82(6):749-55.

18. Yamaguchi A, Tanaka S, Yamaguchi S, et al. Two novel heat-soluble protein families abundantly expressed in an anhydrobiotic tardigrade. PLoS One. 2012;7(8):e44209.

19. Jönsson KI, Rabbow E, Schill RO, et al. Tardigrades survive exposure to space in low Earth orbit. Current Biology. 2008;18(17):R729-R731.

20. Horikawa DD. Survival of Tardigrades in Extreme Environments: A Model Animal for Astrobiology. Cellular Origin. Springer; 2011;21:205-217.
21. BIOKon In Space. International space station. BIOKIS, NASA; 2016.

22. Rizzo AM, Altiero T, Corsetto PA, et al. Space flight effects on antioxidant molecules in dry tardigrades: The Tardikiss experiment. Biomed Res Int. 2015;2015:167642.

23. Jönsson KI . Tardigrades as a potential model organism in space research Astrobiology. 2007;7(5):757-766.

24. Animal Genome Size Database.

25. Boothby TC, Tenlen JR, Smith FW, et al. Evidence for extensive horizontal gene transfer from the draft genome of a tardigrade. Proc Natl Acad Sci USA. 2015;112(52):15976-15981.

26. Koutsovoulos G, Kumar S, Laetsch DR, et al No evidence for extensive horizontal gene transfer in the genome of the tardigrade Hypsibius dujardini. Proc Natl Acad Sci USA. 2016113(18):5053-5058.

27. Hashimoto T, Horikawa DD, Saito Y, et al. Extremotolerant tardigrade genome and improved radiotolerance of human cultured cells by tardigrade-unique protein. Nat Commun. 2016;7:12808. 